\title{
POLITICAL ALIENATION
IRAQ IS A MODEL
}

\author{
Assist. Prof. Dr. Raghad Nsaif Jasim
}

DOI: $10.37648 /$ ijrssh.v10i01.035

Received:04 ${ }^{\text {th }}$ November 2019; Accepted: $6^{\text {th }}$ December, 2019; Published:28 $8^{\text {th }}$ December, 2019

\section{INTRODUCTION}

Knowledge provides man with the opportunity to control oneself, and leads to happiness in positive situations, or Aristotle does not assert: knowledge that says that the rationality of the world is the law of human thought itself when the essential thing in that knowledge becomes its self-support

The opposite of happiness is alienation, i.e. alienation, which in its simple sense: a sense of insecurity, i.e. fear, where the degree of feeling with alienation in the individual depends on the separation of his human existence and his society and from the actions that emanate from it, he loses control over it, and becomes in control of it, he does not feel that he was center of his world and in control of his actions, alienation is: destroying and collapsing close relationships, destroying feelings of belonging to large groups, and also deepening the gap between generations or increasing the gap between social groups.

The question is: Who is responsible for feeling alienated? There is no doubt: responsibility in any location means wisdom, and the latter leads to justice, otherwise it produces injustice that leads to alienation of the individual who is aware of what is going on around him.

The human being is affected by the economic, social, political and security situations surrounding him, certainly the influence is not equal among all individuals to the same degree.
The fundamental values that drive society are influenced by the surrounding circumstances, and the weakness or breakdown of the fundamental values of society leads to the collapse of society, leads the conscious individual to a sense of alienation, and the responsibility for the fundamental values of society is authority, and with the injustice of the latter is the loss of the homeland, which means: Alienation, which may lead to immigration, terrorism and weak loyalty to the homeland, and the people become fertile ground for any destructive attack on it,

Whether material or moral.

This can lead some to the lack of desire for life, the destruction of oneself and others, because the stranger of the homeland is a stranger of the soul, and then the alienation towards the homeland.

The nature of the research required to divide it into two topics; as well as the conclusion that included the results, where the first topic carried the title (The beginning of alienation andits causes), and we explained: that the alienation of the individual began when he moved away from his first nature and the loss of responsible freedom. The second topic, in which we have clarified the Iraqi man's alienation as a result of the unstable situation in Iraq, and the conclusion came to show us ways of dealing with it.

TOPIC ONE: POLITICAL ALIENATION AND ITS CAUSES

First: Conceptual Framework 
Alienation is: the socio-psychological situation that completely controls the individual, making him strange and far from some aspects of his social reality, and the idea of alienation currently dominates on the contemporary literature as well as the history of social thought. controls on

Man was born free, as manifested in the following saying : (When you enslaved people and their mothers gave birth themfree)"i.e., nature is freedom, and man wanted to preserve his nature - freedom because man always tends to nature in the depths of himself.

So the history of human alienation is the history of his search for freedom ,fear is the greatest enemy of man, and it is the

cause of failure, disease and most human relations, as most people are afraid of the past, the future, Ageing, insanity and death, but fear is nothing but a thought in the inner mind of man, which means: man fears of his thoughts. Fear with man begins with awareness, and therefore whenever human consciousness begins to feel alienated, the reason here, because with awareness the feeling of fear begins, and safety is a relative issue for the absence of absolute circumstance, and therefore alienation continues to live within the human being in varying proportions according to the degree of freedomto get his rights .

Alienation is: psychosocial state that completely controls the individual. It makes him strange and far from some aspects of his social reality, and the human being is of course of a social nature. Therefore, he sought from the beginning to conclude an implicit contract with his brother man, and that the solidarity contract gave us a society whose members exchange mutual benefits, and here the human being gave up aspects of his freedom to his brother man, and that the effect of that was positive on the human being, i.e. did not leave a negative psychological impact on the human being, but rather a social positive lies in achieving security and social living, because man by his nature is social.

The stability of society depends on the nature of the political system, and its ability to achieve cohesion and integration among the people despite his multiple affiliations with identity, as the system and violence are two different aspects of life in society, one of which depends on the other.

Societies that have been able to achieve a high level of cohesion and integration among their different components by resolving the contradictions between different social groups have been able to achieve a high level of security and stability.

Societies that have been unable to control existing conflicts have become a common means of political action, and therefore violence and the situation are mixed with the very formative structure of society, whether at the official level or at the popular level, as we can see, especially in systems with limited legitimacy.Violence is frequent in societies where many individuals suffer from a sense of alienation and frustration of all various kinds, and political alienation is; A person's sense of

isolation towards politics and government in his community, and a tendency to think: that the politics of the nation is managed by others and in the interest of others, and in accordance with a set of unjust laws, and that alienation on the basis of that type isolates the individual from society, because he feels that he no longer belongs to him,for reasons beyond his will, but imposed on him by compelling economic, psychological and social conditions, although formally remained connected to society and subject to his rules. However, in practical and psychological terms, it cannot integrate into public life, because it transcends it by virtue of the nature of oppression and arbitrariness integrated with the social structure, which is driven by the major powers that dominate society especially the economic, social and political forces. ${ }^{1}$

Both cohesion and integration in society depends on the political system that governs society, which is the product of the social contract, as the theory of (The social contract) is the source of the basis on which the concept of (alienation) is used in the field of philosophy, Hobbes has shown in the writing of "Dragon": that alienation is: a free voluntary act or it is

${ }^{1}$ Sadiq al-Aswad: Political Sociology , its origins and dimensions, Baghdad, 1991, p. 594-595 
a sacrifice that must be made by the individual for his benefit and interest, and according to Hobbes's belief... the individual acquires more than he loses when he transfers his natural rights to another human being or a council of individuals representing absolute power and sovereignty. The individual in Hobbes' theory can only enter the social contract if he takes away from himself the right to do anything he must do, and moves on to the other who has absolute power and total sovereignty, his natural right to use his power as he wants, in order to preserve his private life. ${ }^{2}$

Rousseau has linked alienation to the issue of ceding or giving up some or all of their rights and freedoms to society, in search of social security within society.As confirmed by Hobbes and Locke, Rousseau has shown that the concept of (alienation) is to alienate the individual and to give or sell, a man who becomes a slave to the other does not give himself, but sells them at least in order to build his life, and that difference in the concept, as Rousseau sees it, between the concept of giving (voluntarily) and selling. Rousseau said: (Alienation) is:the interruption of man from his original nature, which can be: either primitive origins or the intrinsic nature, and overcoming alienation is a return to that essence. ${ }^{3 "}$ Locke's idea of (alienation) was similar to that used by Hobbs to refer to the idea of giving up or delivering and other words expressing the transfer of natural rights and handing them over to the authority of society. ${ }^{4}$

We conclude that both Hobbes and Locke agree on the essence and content of (alienation) which is represented by the idea of abandoning natural rights, handing them over to society as a free voluntary act, and as a sacrifice willingly, and thus (alienation) in that positive sense,

${ }^{2}$ Social alienation and youth, at the link: http://syrianews.com/readnews.php?sy_seq=91253

For more to look: Thomas Hobbes, The Book of Dragons, link: http://www.almaktabah.net/vb/showthread.php?t=2037 6 where it is a prerequisite for the exit of man from Nature's case to the social situation, in order to ensure the establishment of political civil society, and therefore there is no alienation with the act of will.

From the point of view of the researcher who considers that man did not feel alienated as a result of the social contract, because the nature of the contract concluded by man with his brother man is an implicit contract of course made between the sons of society, a voluntary act free did not include sacrifice, but is a process through which the benefit is exchanged between sons of the society, that ensures the achievement of the public

interest sponsored by the general will of the members of society, and through mutual interaction between members of society, and on a daily basis thesocial phenomena have emerged, over time, they became social realities that gave institutional structures, which formally administered the society through the rules and laws that had contributed to the customs and traditions of society, thereby building the State.

The direct democracy of the city state is the model (closest to human nature) for the rule the people and their cooperation with each other. But with the complexity of life and the growing population have emerged as indirect democracy, the rule of the people. But through the popular power of attorney of a number of citizens (deputies) represented by the (legislative authority) that enacts laws and monitors their implementation, i.e. the people who govern and implement, where is the waiver here? Therefore, there is no waiver and therefore there is no alienation resulting from the way the system of government is established.

Therefore, the reason lies in the application, because when the people embark onthe process of informed control on the behavioral orientations of political professionals, the slightest moral fault can overthrow the history and political future of a political official, and we cannot return that collective moral awareness to the religious consciousness alone, nor to the consciousness and the civil task alone, this behavior is due to the political system's contribution to the awareness and interaction of society. And we see that positive contribution only within what Max Weber called (Rational Hegemony), which is basically based on some 
kind of Rational and transparent contracting between the state and society. But we see political alienation: contracting based on personal charisma or traditional religious domination according to Max Weber's theory offers only authoritarian vertical relationships. It is based on the role of (The Shadow of God on Earth) or (Divine Right) as expressed in traditional political philosophy, or based on personal charisma expressed in various ways: speeches (parliamentary speeches), influence through special fashion with the aim of psychological influence on in the members of society, and gaining their confidence and obedience. The domination of society occurs through religious or charismatic domination, depending on the type of traditional or transitional society from traditional to democratic, in which case horizontal hegemony cannot be established on a rational basis in which sovereignty is equal between state law and the control of society, That is, between the consciousness of the state and the consciousness of society, as long as vertical relations are relations of alienation or attempt to impose hegemony through alienation, if we accept with Max Weber: that politics is based on symbolic and material violence under the contract between the traditional and the charismatic, any moral intentions will be negated despite the existence of the concept of (legitimacy), the use of physical, ideological and demagogic mechanisms of violence, even in the context of legitimate violence, will directly refer us to the fact that the symbolic relationship between the state and society is a relationship of authoritarian intentions that imposes monopolistic intentions to absolute power, and absolute power imposes the existence of Ideological mechanisms for legalizing violence voluntarily or involuntarily. ${ }^{5}$

Therefore, the absence of alienation is achieved when the concept of ethics is permanently and consistently present within the behavioral system of the collective consciousness of societies and the governing authority responsible for achieving the collective awareness of society, and that talking about ethics and politics has nothing to do with the practical behavioral sense, but in

${ }^{5}$ Murshid Kari and Max Weber, Politics and Ethics or The Bearded Government, Moroccan Events on 21 January 2013 the sense ,the extent to which politics and morality interact in the political behaviors of the ruling government are reflected in their sense of responsibility derived from true belonging and loyalty to the homeland.

\section{Second: The reasons of political alienation}

The social system refers to a set of interconnected structures, institutions and social practices, which protect, maintain and strengthen the usual ways of acting and act within society, and the social system is a system relatively stable, being institutions,

and patterns of interactions and customs so that they are constantly able to reproduce the necessary conditions for their existence, the concept is due to those realities about society that remain relatively constant all the time, which are cultural patterns, communication relationships and valuable systems. ${ }^{6}$

The preservation of the social order supports the commitment to the values underlying the governance of society, which ultimately lead to the creation of values that govern society, and make it give importance and priority to metaphysical values, and the identification of the values of the masses at the heart of democratic politics and highlights the priorities of values in what it is important for citizens, moreover, the values that promote democracy are participation and a sense of the other, and somewhat distant from the sense of alienation, So mostly the broad valuetrends exert an effective influence in the most explicit policy positions and behaviors.

One way to succeed democracy is: trust, high social value, among the individuals of society, because its existence leads them to be more willing to cooperate with others on political issues, when there is a match between social culture and political culture, political values are subject togeneral social values, and that mitigates from political contradictions. ${ }^{7}$

${ }^{6}$ Jedneez,Ibid P. 407

${ }^{7}$ Jean Berkut, Jean-Pierre Monnier, Elements for Sociology, Translation: AntowanHomsi, Ministry of Culture, Syria, 1994, p. 374-375 
The removal of fear from the human being is not an easy process, as it interferes with the conditions surrounding the human being, which imposes on him priorities that he seeks to achieve and governed by the state of society.

The consensual relationship between the political system and society is conducive to the creation of security and stability in the citizen soul that leads to the reassuring, unafraid and stable soul, then alienation has no place in society, and certainly not absolutely, because there is no absoluteness of the human soul. Iraqi society has lacked security, and felt with fear and the harsh social conditions, due to injustice, social inequity and lack

of economic growth, the loss of social and military security and internal stability all that are a fertile ground for the growth of alienation in Iraqi society. Generations have emerged under these harsh conditions.

These tattered economic, social, intellectual and institutional conditions have led to a dramatic decline in metaphysical values across generations, due to the fact that the process of changing values is strongly linked to the conditions in which current and older generations of society are growing up, Who is now

interested in the material goals, as a result of fear and the absence of government guarantee programs that protect the citizen from any economic setbacks.

In addition, the narrow view of individuals, due to low cultural levels, has become a matter of concern for material and security needs, and to stay away from what is beyond materialism. This reality has been reflected in generations by its reflection on the socialization of generations, but what happened in Iraq has changed somewhat in the culture of society.

It is more like a cessation of the role of the political system in protecting society from the means that divide the members of society, where human motives can be controlled through socialization, which is a process through which the motives of individuals are repeated in socially acceptable directions, in turn, leads to the preservation of the stable political system which is the cause and consequence of the stability of society, and that the democratic political system is effective and influential in society, because it is the result of the development of the procedural rules of the democratic system, namely political trends, standards of conduct, decision-making mechanisms, relations between rulers and governed, and here the ruling system affects the behavior of citizens, by turning nationals into citizens, as embodied in the role of the ruling regime through economic growth that supports democracy, because with underdevelopment it is dictatorship ${ }^{8}$.

This in turn leads to the destabilization of integration and cohesion in society, and in turn reflects on the roles played by individuals in society: such as institutional roles (in family, class, union, etc.), as well as noninstitutional roles (belonging to a group of friends, etc.), and social roles: The range of movement methods in a society that are characterized by the behavior of individuals in the exercise of a special function, and the multiple roles played by the individual in society through groups of a different nature and objectives may lead to the emergence of a phenomenon (Roles conflict)when the role of an

individual in a particular group conflicts with his role in another group is different from the first, as the difference of the class role with the role of the party, and the difference of the sectarian role with the national role $^{9}$, which eventually loses its balance as a result of feeling alienated towards what exists in society.

Social function is always a response to the satisfaction of needs, whether it relates to the natural existence of people or to the civilized values of the prevailing system of society, the social function satisfies social needs at a specific time and situation of society, and in this case can distinguish between the visible function and the hidden function, the first is the functions that

${ }^{8}$ Jean Berkut, Jean-Pierre Monnier, Elements for Sociology, Ibid, , p. 360-361

${ }^{9}$ For more see: Sadiq al-Aswad, A source mentioned above, p. 121, as well as see: Philippe Bro, Political Sociology, Arab Research and Publishing Network, 2014. 
the individuals understand and realize,by the individuals they do, for the other: which the individual does not realize when he performs them. It is natural when a job that no longer responds appropriately to meet the needs addressed to it, and if it is concerned with the preservation of the social structure or the intellectual structures of society, another function emerges to replace it to preserve the society, it is worth noting that whenever there is a social function to satisfy the certain needs also exist the function of refraining from doing something, i.e. it is an activity that is negatively directed towards the existence of social structures and other structures to preserve and sustain them. ${ }^{10}$

This has led to the halting of the process of the development of Iraqi society, and yet the cessation is to go back to all that is negative, since the movement of society resulting from functions and roles in society is determined by the conditions and possibilities of society to move. It's not a situation of destiny, it's not automatic, but society progress is based on reason and reason, result and conscious will of the human being plays basic role, but on the other hand, the will of man is not free, but is constrained by the circumstances that are drawn to some extent by the institutions of society, and the responsible for the management of these institutions is: the political system, and what happened in Iraq is the loss of control of the management of society, as it has lost security and the lack of equitable distribution of economic wealth, weak protection of the law and corruption, among others.

\section{TOPIC TWO : POLITICAL ALIENATION OF THE IRAQI CITIZEN}

Since 1980, Iraq has witnessed an abnormal situation of war, economic blockade, occupation and the genocide of the people through continuous bombings. It was accompanied by the collapse of state institutions and the dissolution of the Iraqi army and the fall of cities in the hands of ISIS, as well as displacement, immigration, killing on identity and living in tents in the desert under temperatures of more than $\left(57^{\circ} \mathrm{C}\right)$ in

${ }^{10}$ Sadiq al-Aswad, Political sociology,, An already .mentioned source, p. 119 the summer and below zero degrees in winter, and there is no doubt in these harsh conditions there is a collapse in all state's institutions, implicitly, can be considered Iraq as a failed state, and this is reflected in the failure of the authority to achieve and provide protection and security to the community by establishing the pillars of internal peace, as well as providing external peace to society to assure for him that he will not exposed to external danger, as well as to work to achieve progress, as well as getting the dignity, pride and greatness of society, in addition to the weakness or absence of the law, this means the absence of a set of rules of conduct thatinclude forcing to walk with it, and set by individuals in society, and those rules are intended to establish order and justice in social relationships.

All these factors have destroyed the Iraqi human beings, and the symptoms of these epidemics are: changing the basic values of the society, such as honesty, tolerance, cooperation and other human qualities, and that values as psychologists describe it: they are mental processes that include the issuance of a judgments that the individual learns from trying to achieve balance in his social relationships based on mental development,

and that values develop through stages from childhood to adulthood, starting with the pre-moral judgments, and ending with the development of the individual's personal conscience and its own value, and his realization that what is morally correct may not necessarily be legally correct. ${ }^{11}$ The sources of value acquisition are family/first, followed by school, society, peers, cultural and media, and ultimately give a coordinated and coherent value system. The change in the basic values of the individual takes place in his early years in response to the social and economic situation at the stage of building a personality.

${ }^{11}$ Qasim Hussein Saleh, Iraqi Personality, TheAppearance and Essence, Iraq, Baghdad, Difaf of Printing and Publishing, Baghdad, p. 103 
As the priorities of values evolve, they tend to withstand in front of subsequent changes in social conditions. $^{12}$

So the political system, family and society are responsible for social regionalization, and the absence of this leads to a state of alienation in the social pattern, including a state of loss of control and the dissolution of social values, where the individual tries to search for a system of his life, but fails to find that system as well as fails in making plans for the future, which creates a vast gap between the real world that rejects it and the ideal world of values that he seeks, and that leads to internal alienation, which is the feeling of the individual to separate from himself, his values, principles, beliefs, values, goals and ambitions, and this is reflected by the feeling of the individual with ineffectiveness, because of the distance between the gap between him on the one hand, and his environment on the other hand.

A serious decline in the metaphysical values that governed the conduct of individuals in society can be explained by the fact that the analysis of changes in values in a comprehensive manner is presented to us by . Ronald Inglehart, and the interpretation of the change of values is based on two realities: the priorities of the values of the public are determined by the theory of scarcity, which it states that individuals give the highest value to relatively scarce things, i.e. when something of value cannot be obtained, its value doubles, but if supply increases at the level of demand, it becomes guaranteed, and attention turns to other things that are still scarce, for example, water is precious goods in times of drought. But when the rain returns to rain naturally interest fades in water.

The other element of Inglehart's theory is the premise of social regionalization, which states that to a large extent, a person's priorities of values reflect pre-adult conditions.

It includes: the conditions of personality-building, both the direct situations in the family of the person, and the

\footnotetext{
${ }^{12}$ RuselJiyeh Dalton, Role of Political Citizen in Western Democracies, Translation: Ahmed Yaacoub Al-Majdouba, Mahfoud al-Jubouri, Amman, Dar alBashir, 1996, p. 102
}

political and economic conditions of society in its broader range, and the integration of both assumptions: (scarcity and social regionalization) results in a general model of change of values, and the priorities of the fundamental values of the individual are

formed in his early years in response to the social and economic condition at the stage of personality building,

and once the priorities of values evolve, they tend to withstand in face of subsequent changes in social conditions.

Changing core values leads to a change in the values, attitudes and behaviors of the individual, and a change in the overall values of the individual leads to a change in the important objectives at the individual level, which guide human behavior, and thus the behavior and objectives of society. ${ }^{13}$ But we do not miss here what the anthropologists confirmed, where they showed their willingness to cancel the psychological generalizations, and to advocate for cultural relativism that does not issue a judgments, which ignores the fact that some of the problem of continuous social rehabilitation culturally is more problematic than others, and there is another idea is that cultural profiling limits the individual's attitude rather than the economic, social and political situations that surround the individual. ${ }^{14}$

Personal construction is: a complex hypothesis construction used to interpret two basic questions: the stability and consistency of an individual's behavior over time and through situations, and the other: differentiation or difference in the behavior of individuals who are exposed to the same situations, and the hypothetical construction of personality is meant: it is abstraction that refers to the inner case of the individual or his environment and his relationships with others, which include: his educational history, the biological components and the ways in which complex

\footnotetext{
${ }^{13}$ Russell J. Dalton, aforementioned source, P.100-101

${ }^{14}$ Group of authors, Political psychology, translation: Abdul Karim Nassif, Syria, Syrian General Book Commission, 2007, p. 361
} 
events are organized, which affect a person's response to social and environmental alerts. ${ }^{15}$

Values are at the heart of human actions, as citizens set a general framework for making those decisions (or to arrange ambition and goals) by arranging values in the setting of a value system that gives them rankings based on their importance to the individual. Sociologists differed in their vision of values, ranking them from most important to the least important, and suggested the concept of peace or value pattern, which means: the set of interrelated values that regulate the behavior of the individual and his conducts in a hierarchical order of what the individual espouses and what governs his behavior, which we mean by the (value system) and content order of the value systems from varies from community to another.

In Muslim societies, for example, values are at the top of that system, while material values are at the forefront of Western societies.

These value systems have important social and psychological functions, including: they link the parts of culture in society to look consistent, give a common mental understanding of his members, provide them with the meaning of life, methods of achieving goals, Sentencing individuals, events and things, what is desirable, and undesirable, as sociologists believe that the integration of culture in a society depends on the harmony of values with each other in that society is a direct relationship, and that values are the ones that have a great influence on the culture of society, and that their influence depends on the degree of flexibility of the format, or the value system, and the extent of its cohesion when society exposes to new intellectual changes or major events: war and occupation, for example. ${ }^{16}$

Changing the fundamental values of society leads to the altruism of some social and personal goals, as well as the means to achieve those goals, as individuals who give priority to freedom, equality and social harmony change their ambitions, and this is reflected in the

\footnotetext{
.${ }^{15}$ Qasim Hussein Saleh, aforementioned source, p. 207

${ }^{16}$ Qasim Hussein Saleh: Aforementioned Source, p. 102
}

direction of their actions and behavior as the policies that promote those values change. The emergence of opportunistic aggressiveness among some, when illegal means are available, as a result of weak law enforcement- and here the conscious individual suffers from alienation as a result of separation from his human existence, from his society, and from acts emanating from individuals, he loses or departs from his ambition, because the arising values in society determines his ambition, and he does not feel that he is the center of the world, and control in his actions, and the individual feels the failure to understand, and accept the values and prevailing standards in society, and his inability to integrate into it as a result of his lack of confidence in society and his various institutions, and the conscious individual here feels with alienation, as a result of destruction and termination the close social relationships, breaking the feelings of belonging to the large group as deepening the gap between generations or increasing the gap between social groups from each other. ${ }^{17}$

Accordingly, social solidarity has almost disappeared, owing to the breakdown in values, such as respect, work ethic, true religiosity and other values that guide human behavior, and certainly the ratio is not absolute. But it is a high percentage, which has led to the alienation of generations, because generations that have emerged on material values have acquired values that are difficult to adapt the generation that emerged with metaphysical values (moral)

The absence of fundamental values leads to the individual's sense of alienation resulting from the separation of the individual from one's own self - from his values, principles, beliefs, goals and ambitions - and this is reflected by the individual's sense of ineffectiveness, because of the gap between oneself on one hand and his environment on the other, and then a

\footnotetext{
${ }^{17}$ YounisKarima, Psychological Alienation and its relationships with academic adaptation among University Students, Unpublished Master's Thesis, MouloudMamari University, Faculty of Humanities and Social Sciences, Algeria p. 3
} 
sense of loss of security and fear is generated, which leads to psychological internal alienation.

Social interaction is one of the most important pillars through which individuals can achieve psychological integration through the social environment in which they live, where this part greatly affects the determination of the fate of individuals in different areas of life, and the separation of the individual from its frame of reference represented by society to create feeling of alienation. ${ }^{18}$

The frustration of the individual is: the feeling that he feels when he fails and fails to achieve his goal or the set of goals that he was seeking to achieve, because of different obstacles and these barriers may be personal or public related to society and the environment surrounding the individual, as some opinions in psychiatry: wars and crises and instability in society is a cause of frustration, as they are obstacles stand in front of achieving goals, and everything that applies in the case of frustration applies to the situation of deprivation in the causal relationship at the personal level of the individual's personal behavior. As for disappointment, it is almost the same word for frustration, which means: the disappointment of the individual's efforts to achieve some of his goals, and to obstruct his quest towards an aim, whether conscious effort or unconscious, and thus it is clear before us now the magnitude of the impact of the destructive

sabotage that can be caused by frustration, disappointment and deprivation in determining the behavior of the individual, and directing his activities and relationships in society. ${ }^{19}$

Knowing that the individual's tolerance of disappointment, frustration and deprivation requires him to overcome feelings of anger, anxiety and boiling, and the impatience, anxiety and tension that arise and accompany him every day, because of these three

\footnotetext{
${ }^{18}$ AbdulLatif Mohammed Khalifa, Studies in the psychology of alienation., Dar Ghraib Printing, Publishing and Distribution, Cairo, 2003, P.107_108

${ }^{19}$ Baqir Yassin, Iraqi Individual, Iraq, Erbil, Arras

.Printing and Publishing House, 2010, p. 30,31,32,33
}

factors: because of his failure, and even his inability to achieve his personal and instinctive desires, including: food, drink, security and decent, stable living, as well as his failure to reach other desires, we realized the extent of the bitter, terrible and cruel suffering and the feelings of anger, distress and tension experienced and lived by man in Iraq, which have leaked into his soul and behavior through the centuries, years, days and even today.

Here, the conscious individual who suffers from alienation is unable to change his reality, so he withdraws from society and takes different forms depending on the situation of the individual, for example: intellectuals and specialists, and migration is carried out if the situation is appropriate or selfreliance, as well as manifestations of alienation towards the apathy toward social events ${ }^{20}$, as psychological and cultural studies show interests in ethical behavior to be adhered to in thought and awareness. However, with frustration and tyranny, internal retreat occurs in the case of alienation, and this state of alienation can be expressed by some kind of abnormal, deviant behavior, including aggressive or criminal behavior. ${ }^{21}$

Violence takes many forms: moral and material.

The early dysfunction of the family, represented by the presence of only one parent, is reflected in the behavior of the individual, which depends on the first family cultural patterns, as well as on the experiences of childhood derived from society and later in school, and in the case of Iraqi society, the experiences of early social rehabilitation contribute to find patterns of illadapted personality. The difficulties experienced by one of us in the early family rehabilitation stage can contribute tothe development of forms of loyalty and ultimate social commitmentor protest.

In negative family situations, the child lives in a kind of social discontent, and is expressed more in the form of

\footnotetext{
${ }^{20}$ AbdulLatif Mohammed Khalifa, Political Psychology , An already mentioned source., p. 108

${ }^{21}$ Group of Authors, Studies in the Psychology of .alienation, Source Already Mentioned, p. 356
} 
personal alienation and problematic situations of

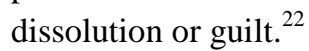

The sense of social discontent is reflected in the form of personal alienation, which means the absence of social adaption, including political loyalty, in the absence of the initial social cohesion that the individual lives within the basic family, and then the experiences and experiments in the society in pre-adolescence stage ${ }^{23}$ Alienation may generate a sense of complacency, which is one of the expected consequences of alienation, as thealienated person chooses complacency and accepts the principle of fait accompli instead of withdrawing. ${ }^{24}$ Moreover, the ongoing war of genocide at all levels, whether it be the loss of real status at work, which is commensurate with the efficiency of the individual, the progress of unqualified opportunists and fundamentalists in illegal ways, or sectarian displacement or migration outside the country or victims that go as a result of continuous bombings, identity killings, kidnapping, ransom and confiscation of other people's property, because of sectarian, religious or ethnic reason.

The occupation, which generates a sense of loss of security, dignity and humiliation, all this generates a sense of political alienation, and that leads to the individual's sense of alienation, as a result of the individual's exposure to psychological trauma as a result of the extraction of certain things and the people he loves (work, mother, love, occult forces, or society), the social system changes in terms of interrelated social structures, institutions and practices, which protect, maintain and strengthen the usual ways of acting and acting within society.

Here we mention: political data are related to other social phenomena in society, such as culture, needs, social differences and behaviors to form values that express thesocial dynamics, which is a natural advantage that reflects the dynamics of societies in their

${ }^{22}$ Group of authors, aforementioned source, p. 258-259

$$
{ }^{23} \text { Ibid, p. } 357
$$

${ }^{24}$ AbdulLatif Mohammed Khalifa, aforementioned source, p. 108-107 growth and development to some extent reflect the process of social change, which is an imperative for societies to transition from one situation to another, and the process is

very important in its reflection on the political change of the state, and diagnosed on its political causes, pace and nature. ${ }^{25}$

The alienation of moral authority has been negatively reflected. In the absence of moral authority in society, patterns of loyalty to factional relations can enter into a conflict situation that one may support final loyalty. As for the basic family, the peer group or the group with which they live, loyalty is related to moral authority, and those who are forced to complacency and obedience, they often lack such a sense of loyalty. ${ }^{26}$

In light of this, the national culture has been absent to be replaced by the subculture, as a natural result of the conscious majority, as the separation of the individual from himself is a sense of failure to understand, realize and accept the prevailing values and standards of society, and his inability to integrate into it, as a result of his lack of confidence in society and his institutions. The separation of the individual from his frame of reference, which is represented by society, creates a sense of political alienation, and that generates the individual's sense of loneliness, and the attempt to move away from the social relations prevailing in the society in which he lives, which may generate rebellions among some young people and groups of intellectuals against society and his institutions and organizations, the alienation of the individual in his homeland is harsher than the alienation of the immigrant from his country, and may generate a sense of the feeling of some that life is meaningless, and that it is free of the goals that deserve to live for it, and seek it, thus being prey and fertile ground for extremist stray ideas, which may be the price of his life and the lives of thousands of innocent people to serve the purposes of enemies. The absence of a national culture as a result

${ }^{25}$ Academy of Social and Human Studies, Issue 8, 2012,

p. $68-74$

${ }^{26}$ Group of Authors, Political Psychology, Source Already Mentioned, p. 356 
of the change in social functions and roles of the individual leads to the replacement of the subculture instead of the national culture, and here the delay of loyalty to the homeland for the benefit of subaffiliations, and the achievement of security in all its aspects leads to the departure of the individual from repeating the words: What is the use of my large homeland I live in it as despicable and sad, replaced by loyalty to the homeland.

\section{CONCLUSION}

Iraqi society has suffered a lot, if we recall the continuation of many successive wars, bloody massacres and natural disasters: devastating floods and deadly epidemics: plague and smallpox, the invasions of greedy foreign armies, mass displacement of population, injustices of tyrant rulers and the unjust dictatorial regimes, left behind by the horrors and the constant crushing of the souls and interests of human beings and their dignity, and the destruction of their hopes and aspirations, and preventing them from achieving their life and human goals, we say all that and what happened on the territory of Iraq, as well as the bloody military coups and their disastrous consequences in $20^{\text {th }}$ century to realize: the existence of frustration, disappointment and deprivation in Iraqi life is almost present and present, and continues over the days and years, and is the bad end, bad and trimmed party that has haunted human life in Iraqi society at the most important stages of history for more than 5,000 years even today, it is only natural that the behavior resulting from deprivation and frustration is generated by the most Iraqi individuals, and perhaps this has led us to understand the causes of Iraqi behavior and his sense of alienation.

The alienation suffered by the Iraqi human being, who is aware of the disparity, is: a natural consequence of the security collapse, the loss of wealth and the absence of the basic values of human and national building, there is alienation among the generations in Iraqi society. The generations of the monarchy, paid off in the 1970s, left their mark on the generations that followed, in varying proportions, conflicting or opposed to the scarcity and wars that led to the collapse of educational and security institutions, intellectual structures, social structures and basic values of society, and led to the alienation of the Iraqi human being who is aware of what is going on around him, and this is reflected in the sense of social discontent, and this is reflected in the form of personal alienation, which means the absence of social adaption, including: political loyalty, in the absence of social cohesion.

Frustration, disappointment and deprivation, with the absence of the initial social cohesion of the individual in the primary family, and then the experiences and experiments of the individual in society, led to;

1- The nature of cruelty, violence, aggression and convulsions, at which point the process of engaging in terrorism may then not be difficult.

2-Loss of the importance of school and family in the prevention of crime, terrorism and drugs.

3-Poor maintenance of family ties and cohesion and the absence of community reform by state institutions.

4-The absence of proper religious awareness, and the growth of narrow sectarianism due to the occupation.

5-The absence of serious intellectual dialogue, the reform of intellectual structures with conscious minds and a policy away from violence.

Protecting the human being from alienation requires sincere, painstaking and tireless efforts from the knowledge and understanding how to reform the social, intellectual, economic, institutional and demographic structures so that Iraqi society can rise up, and he needs patience, prudence and long time, as the human effort is summarized against his alienation in achieving the touch of the human self with its depths through its human essence, and this is achieved with the positive attitude of the human self in its ability to fight the fierce battle to end the negative effects of the wars and the economic blockade imposed on Iraq and then the occupation of Iraq and the subsequent violence and that's the end of the alienation. 